\title{
FUNNEL CHEST: ITS EFFECT ON CARDIAC FUNCTION*
}

\author{
BY \\ RUSSELL HOWARD \\ From the Royal Children's Hospital, Melbourne
}

Funnel chest, with its considerable sternal depression and obvious interference with the topography of the heart, has for some time been made the subject of the attractive paradox that, in the vast majority of cases, it has no effect on cardiac function. True, it is conceded that the deformity may in rare instances be responsible for decompensation severe enough to cause congestive failure but there exists the greatest reluctance to attribute to it any less dramatic evidences of interference with the heart's action. The all or nothing rule seems to be invoked.

There are, however, recent writers who take what seems to be a more logical stand in suggesting that diminished exercise tolerance is common in cases of funnel chest and that cardiac incompetence is its cause. Such opinions have been expressed by Lester (1950a, b, 1954), Ravitch (1951), Wachtel, Ravitch and Grishman (1956), Chin (1957) and the present author (1955). These statements are made in reporting details of large series of cases personally treated by the authors.

The essential feature of the deformity of funnel chest is a depression of the sternum, most marked at the sternoxiphisternal junction. In the funnelchested infant this area retracts markedly on inspiration but the paradoxical movement progressively decreases until at about the age of 4 years it is replaced by orthodox movement of small amplitude. Continued chest development is characterized by the failure of the midline anteroposterior diameter to increase commensurately with the growth of the more lateral parts of the chest, i.e. the funnel becomes deeper. During this period the heart is undergoing the normal increase in size with age, with the result that eventually it may suffer compression between the sternum and the vertebral column. Although at times, this pincer action may be diminished by displacement of the organ to the left, the effect on cardiac function is similar to that of constrictive pericarditis.

\footnotetext{
* A paper read at the meeting of the British Association of
} Paediatric Surgeons held in London in July, 1958.
I have had the opportunity of examining and assessing over 400 patients with funnel chest but it is the 90 of these on whom I have personally operated who provide striking clinical evidence that before operation they were labouring under a physical as well as a psychological handicap. During the early post-operative period the statement is spontaneously volunteered by a high proportion of patients or parents that exercise tolerance has already greatly improved. At this time the vital capacity is still below its pre-operative level, thus rendering unlikely any explanation based on improved respiratory function. In most of these cases direct questioning before operation had failed to elicit a history of any interference with effort. This is, of course, due to failure to appreciate the effort of which a particular child should be capable, so-called normal limits being very elastic.

Ravitch (1951) reported the very convincing instance of a man, 28 years of age and suffering from severe funnel chest deformity, who developed auricular fibrillation and congestive failure with no other cause apparent. Complete recovery and return to strenuous work followed operative relief of the funnel chest.

A suggestive although uncommon symptom is precordial pain on exertion. Although many may discount the inference that this pain is of cardiac origin, the fact remains that all four cases complaining of pain were completely relieved by operation.

In an endeavour to demonstrate graphically interference with cardiac anatomy, angiocardiography has been performed on selected patients. The findings in two representative cases are given below.

\section{Case Histories}

Case 1. S.K. was a girl of 10 years with a moderately severe grade of funnel chest. A plain radiograph of the chest demonstrates the absence of cardiac displacement in the postero-anterior film (Fig. 1). The lateral view shows apparent impingement of the lower part of the sternum on the cardiac shadow (Fig. 2); as there is no displacement of the heart to the left this should indicate 


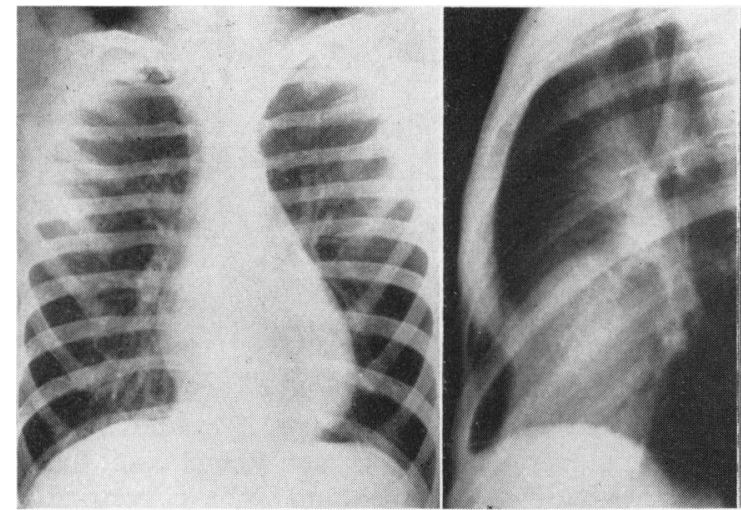

FIG. 1.
FIG. 2.

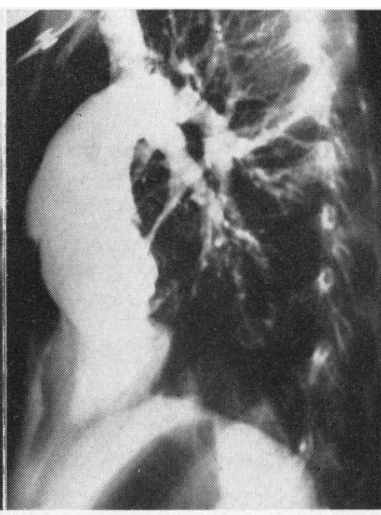

FIG. 3.

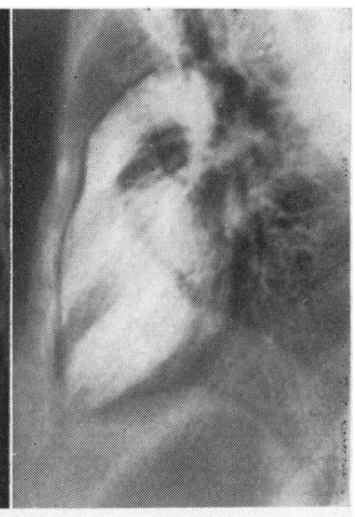

FIG. 4.

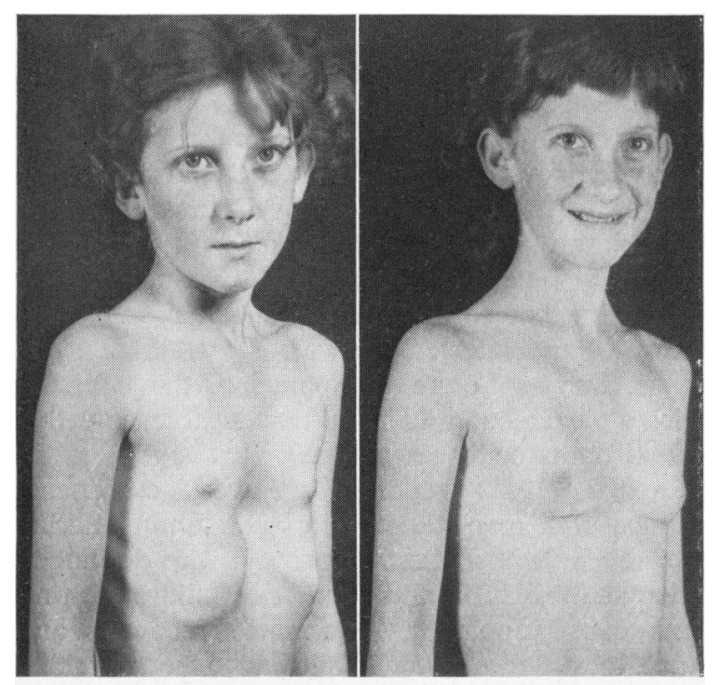

Fig. 1.-Case 1. Postero-anterior film showing absence of lateral cardiac displacement.

Fig. 2.-Lateral film: impingement of sternum on cardiac shadow.

FIG. 3.-Pre-operative lateral angiocardiogram illustrating indentation of right ventricle.

FIG. 4.-Post-operative lateral angiocardiogram showing restoration of normal cardiac outline.

FIG. 5.-Case 1. (a) Moderately severe funnel chest.

(b) Post-operative clinical appearance.

Fig. 6.-Case 2. Postero-anterior film showing cardiac displacement to left.

FIG. 7.-Lateral angiocardiogram: 'negative shadow' of unfilled left ventricle impinges on right ventricle.

FIG. 8.-Filled left ventricle shows filling defect caused in right ventricle.

FIG. 5A.

FIG. 5B,

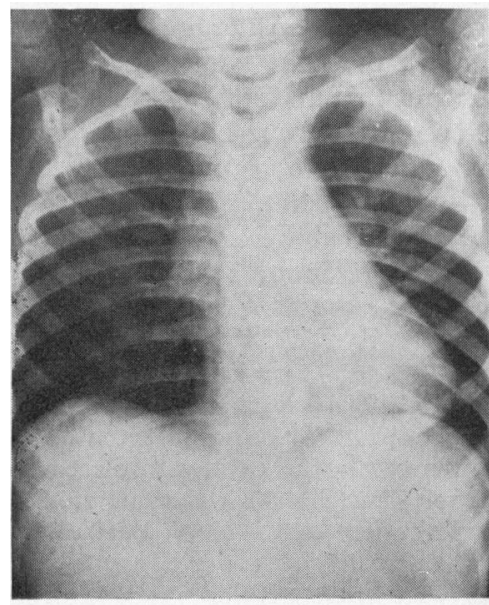

FIG. 6

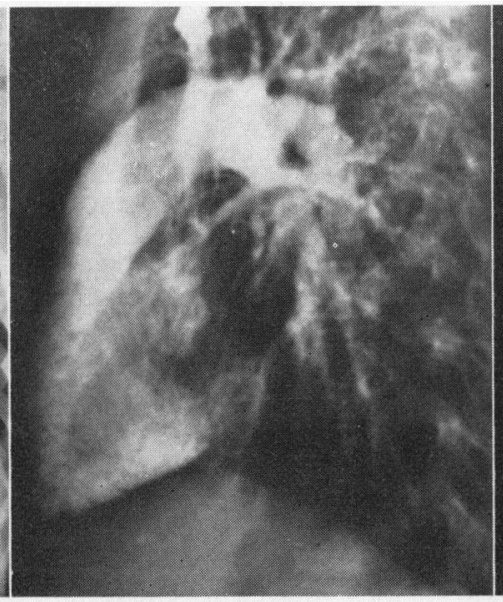

Fig. 7.

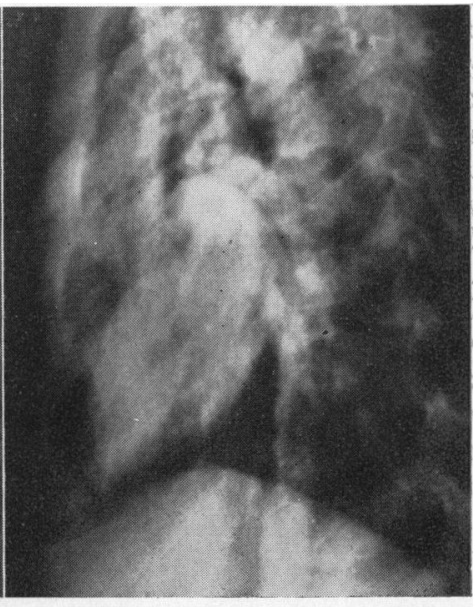

FIG. 8 .

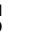


a genuine compression. Confirmation is obtained from the lateral angiocardiogram which shows the sternum deeply indenting the wall of the right ventricle (Fig. 3). Fig. 4 shows the correction of this anomaly as seen in an angiocardiogram taken some 12 months after operation whilst in Figs. 5a and $b$ the appearance before operation and the clinical improvement in the deformity afterwards is noted.

Case 2. H.E. was a girl of 4 years with a gross funnel chest in whom the heart is displaced to the left (Fig. 6). The angiocardiogram shows how, in the rotated heart, the stoutep-walled left ventricle is actually pushed into and causes a filling defect in the right ventricle. Fig. 7 illustrates the 'negative shadow' of the unfilled left ventricle producing this result, whilst in Fig. 8 the filled left ventricle is seen to be exerting the same effect.

These considerable deformities surely must cause diminution in the capacity of the right side of the heart which, whilst not affecting the patient at rest, will take its inevitable toll of exercise tolerance. One would expect that, in response to exertion, right atrial pressure would mount and cardiac output fail to increase to a degree commensurate with requirements.

The estimation of cardiac output on exertion was performed in two cases by Wachtel et al. (1956). One showed no gross abnormality but the other, a patient with severe deformity and gross exercise intolerance, showed exactly the findings anticipated above (even to the extent of cardiac output actually decreasing on exertion). Post-operative readings are recorded in neither case but complete relief of symptoms was effected by operation.

The electrocardiographic findings have been far from constant in the present series. However, a number of the more severe depressions have had an inverted or flattened T-wave in Lead 11, and again the significant fact is the return to a normal pattern following operative intervention.

From the above emerge certain incontrovertible facts. These are that the heart is frequently com- pressed by the sternum in cases of funnel chest; that marked deformity and diminution of the capacity of the right ventricle may thereby be produced; that failure of cardiac output to increase with exercise has been demonstrated in at least one such case; and that relief of both cardiac deformity and exercise intolerance have been proved to follow operation. Surely this is sufficiently suggestive of interference with cardiac function to place the onus of proof upon those who deny its occurrence.

The important question remains as to how frequent is this occurrence. The author's firm impression, based on the clinical improvement in the early post-operative period, is that it is a common event and one which may be confidently expected to yield to the routine operation performed for funnel chest.

\section{Summary}

The question of post-operative improvement in exercise tolerance is discussed on the basis of 90 cases of funnel chest observed in pre- and postoperative phases.

The conclusion is drawn that exercise tolerance is improved in a high percentage of cases.

Proof is adduced of interference with cardiac volume caused by pressure of the depressed sternum.

It is contended that decreased exercise tolerance in cases of funnel chest is due to interference with cardiac output.

I most gratefully acknowledge the enthusiastic help of Dr. H. G. Hiller, Director of Radiology at the Royal Children's Hospital, Melbourne, in connexion with the angiocardiographic work to which so much reference is made in the text.

\section{REFERENCES}

Chin, E. F. (1957). Brit. J. Surg., 44, 360.

Howard, R. N. (1955). Med. J. Aust., 2, 1092.

Lester, C. W. (1950a). J. thorac. Surg., 19, 507

Lester, C. W. (1950a). J. thorac. S

(1954). J. Amer. med. Ass., 156, 1063.

Ravitch, M. M. (1951). Surgery, 30, 178.

Wachtel, F. W., Ravitch, M. M. and Grishman, A. (1956). Amer. Heart J., 52, 121 . 